\title{
Composition of Individual Particles in the Lower Troposphere Determined by Microprobe Technique
}

\author{
By Yutaka Ishizaka and Kenji Isono \\ Water Research Institute, Nagoya University, Chikusa-ku, Nagoya, 464, Japan \\ (Manuscript received 13 December 1979, in revised form 5 June 1980)
}

\begin{abstract}
Aerosol particles were collected with impaction technique at altitudes up to $3.0 \mathrm{~km}$ over three different locations in Japan: urban area (Nagoya), mountain (Mt. Norikura) and ocean (South Okinawa region). Individual aerosol particles larger than $0.5 \mu \mathrm{m}$ in diameter (at 0 percent relative humidity) were analyzed with an electron microprobe. Elemental composition for silicon, sodium, and sulfur contained in collected particles were as follows: (1) Over Nagoya and its vicinity, the aerosol consisted often of particles rich in silicon and/or sulfur in and above mixing layer. (2) At the summit of Mt. Norikura, the aerosol consisted of particles rich in sulfur when convective activities were strong, whereas particles containing silicon and sulfur in large relative weight fractions and sodium in very small amount during nocturnal subsidence conditions. (3) Over the South Okinawa region, two regimes were clearly delineated: The aerosol consisted mainly of particles having the composition similar to the composition of sea water in marine layer, whereas particles having large relative weight fractions of silicon and/or sulfur as compared with the composition of sea water above the marine layer. The relative contribution of silicate, sea salt, and sulfate components in individual particles was estimated from the elemental composition for silicon, sodium, and sulfur contained in their particles. The result of these analysis suggests that mixed large particles $(d \geq 0.5 \mu \mathrm{m})$ containing silicate and sulfate in large relative weight fractions and sea salt in a minor constituent distribute widely in the free atmosphere over the Japanese Islands from Honshu to Okinawa.
\end{abstract}

\section{Introduction}

Tropospheric aerosols can play a significant role in atmospheric processes such as nucleation of cloud drops and ice crystals, and radiation energy transfer. For a better understanding of the influences of the aerosols on such atmospheric processes, it is indispensable to know the composition of individual particles as well as their sizes and concentrations.

Some attempts have been made to determine the composition of individual particles in the troposphere. Among them, an investigation made by flame photometry has revealed that the upper tropospheric air contains only a small number of sea salt particles (Bodhaine \& Pueschel, 1972). Examinations made with chemical test method have indicated that sulfate-containing particles distribute widely in the troposphere (Georgii \& Vitze, 1971; Bigg, 1977; Ono, 1978). Besides these, studies on the bulk chemical composition of tropospheric aerosols have suggested that silicate-containing particles must form an important part of the tropospheric aerosol (Cadle et al., 1969; Gillette \& Blifford, 1971; Delany et al., 1973). However, relatively little information about the contribution of continental component to individual particles of tropospheric aerosols is available.

Over the last few years, we have developed the method of quantitative analysis of individual particles by the use of an electron microprobe (Ishizaka et al., 1976). This method was applied to individual particles in the lower troposphere over Japan. This investigation will give us valuable information on the relative contribution of continental, marine, and sulfate components contained in individual particles of tropospheric aerosols. This paper presents the results of a study on material composition of individual 
particles collected at altitudes up to $3.0 \mathrm{~km}$ over the urban area of Nagoya and the ocean of South Okinawa region and at the summit of Mt. Norikura.

\section{Sample collection}

The aerosol samples were collected with impaction technique on board a two-engined aircraft. Fig. 1 shows the aerosol collector used on the aircraft. An impactor is attached to the end of the brass pipe connected with an orifice type flow meter and a suction pump. The pipe was designed to set the impactor at a position $40 \mathrm{~cm}$ below the fuselage and in the air free from contamination from the engine exhaust only during sampling period. The intake nozzle was made isokinetic at the speed of the aircraft. The aircraft speed was about $140 \mathrm{kt}$ and the impactor flow rate was $6 \mathrm{l} / \mathrm{min}$. Constant flow rate corrected for the pressure and the temperature of drawing air was obtained by manual adjustment in flight. The theoretical collection efficiency of the impactor is $50 \%$ for particles of $0.3 \mu \mathrm{m}$ in diameter (Ranz and Wong, 1952). Aluminium plates or beryllium plates (purity, $99.99 \%$ ), on which aerosol particles were collected, had been carefully cleaned and inserted into the impactors on a clean bench in the laboratory. The impactors were kept in a carrying case. Each impactor was screwed on the pipe before use. Each sample collection required 30 to 180 seconds. Samples were also collected for electron microscope examination onto collodion-coated grids and for optical microscope examination onto slide glass plates coated with a thin layer of silicon oil using

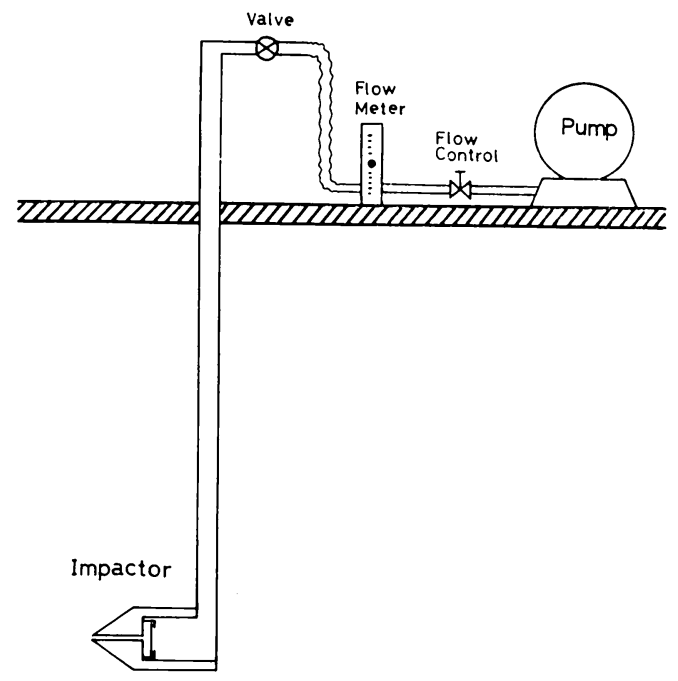

Fig. 1 Aircraft aerosol sampling system.

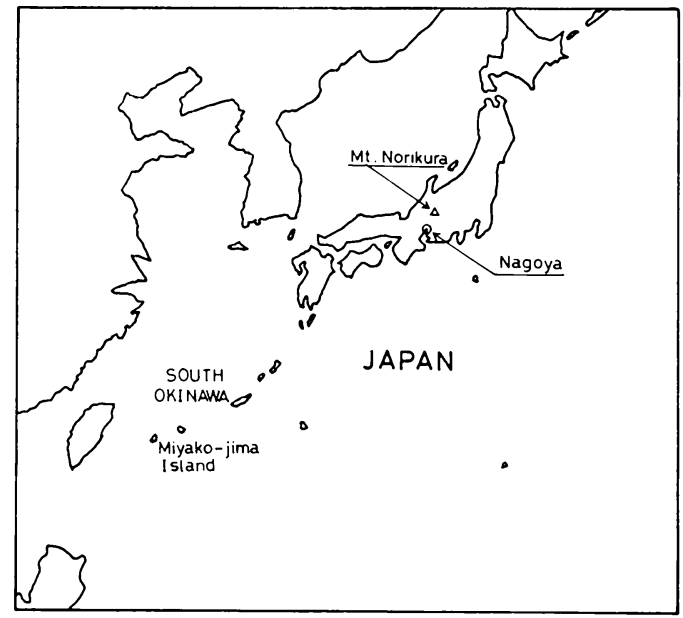

Fig. 2 Locations of Nagoya, Mt. Norikura, and South Okinawa (Miyako-jima Island).

the aerosol collector.

Aerosol samples were obtained at altitudes up to $3.0 \mathrm{~km}$ over urban area and ocean, four flights were made over the urban area of Nagoya and over the sea south of Nagoya (Ise Bay and the eastern Pacific Ocean) on 11 December 1974 and 15 and 16 March 1976; and seven flights were made over the ocean of the South Okinawa region, about $1,300 \mathrm{~km}$ south of the Japanese Islands, on 26 and 27 February 1974 and 20, 25 , and 26 February 1975. Acrosol samples were also collected by means of a single stage impactors (the $50 \%$ cut-off diameter of the stage, $0.3 / \iota \mathrm{m}$ ) at the summit of Mt. Norikura $(2,770 \mathrm{~m}$ above sea level), which is one of the highest peaks of the mountaineous region of the Main Island of Japan (Honshu). Sampling was made in the period of 13 to 22 June 1972 and in the period of 21 to 28 June 1973. Furthermore, sampling on the ground was made in Nagoya in 1974 to compare with aerosol samples described above. Fig. 2 shows the collection sites.

\section{Analysis}

Individual particles larger than $0.5 \mu \mathrm{m}$ in diameter (at 0 percent relative humidity) were examined with an electron microprobe (Model JXA-5A, Japan Electron Optics Laboratory) equipped with three dispersive channels. The collecting surfaces on which the aerosol was collected were vacuum-coated with a thin layer of carbon in order to prevent charging of the particles and consequent distortion and deflection of the electron beam. At first, major elements 
present in individual particles were qualitatively determined using a static electron beam and moving the diffracting crystals (RAP, PET, and LIF or STE) of the three X-ray spectrometers through their effective wavelength ranges. Then quantitative analysis for silicon, sodium, and sulfur was performed on all three spectrometers simultaneously. Silicon and sodium intensities were measured on RAP spectrometers and sulfur on a PET spectrometer. All the analyses were made with the electron beam of a $4 \mu \mathrm{m}$ spot size. In order to prevent vaporization or migration of particles due to heat generated by the beam, silicon, sodium, and sulfur intensities were measured at the low accelerating voltage, $15 \mathrm{kV}$, and at the weak beam current $0.01 \mu \mathrm{A}$ on brass. Relative weight fractions (r.w.f.) of silicon, sodium, and sulfur contained in individual particles and their concentrations in weight percent were determined from X-ray intensity data measured on each particles by the described briefly in the Appendix. In order to supplement the result of electron microprobe analysis, the appearance of individual particles was examined with the electron microscope and the particle growth with relative humidity by means of the isopiestic method.

\section{Result}

\section{(a) At Nagoya and its vicinity}

Fig. 3 shows major elements contained in individual particles collected on the ground at Nagoya. There was a relation between their shapes and elemental composition of individual particles. The major elements contained in particles of intricate chain forms and liquid or semiliquid types were carbon, nitrogen, and sulfur, those in opaque-spherical particles carbon, sodium, and sulfur, and those in irregular solid particles carbon, sodium, magnesium, silicon, and sulfur.

The Si:Na:S ratios of individual particles collected over Nagoya and its vicinity are shown in Figs. 4a \& b, 5a, b, c \& d, and 8. Each dot plotted in the diagrams indicates r.w.f. of $\mathrm{Si}, \mathrm{Na}$, and $S$ contained in individual particles. In these figures, the r.w.f. values for the composition of continental material and sea water are marked with an open rectangle and a cross, respectively.

On a winter day when samples of Fig. $4 a \& b$ were collected, the weather was fine and the visibility was larger than $50 \mathrm{~km}$ on the ground in Nagoya. The strong north-west wind blew all through the day. It is seen from Fig. $4 a \& b$ that

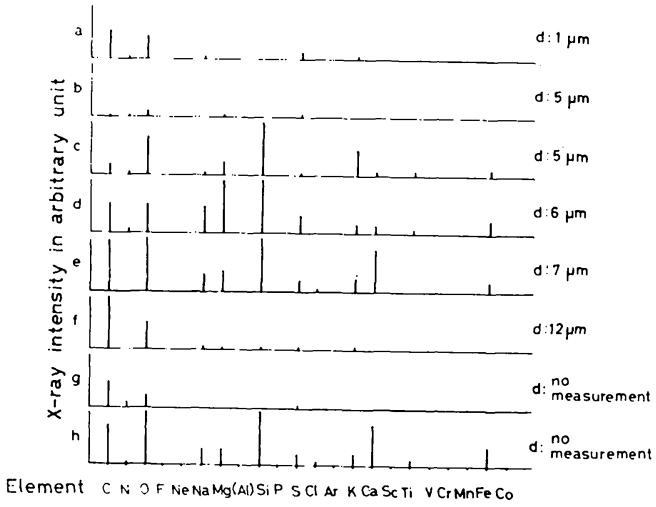

Fig. 3 Elements contained in individual aerosol particles collected at Nagoya at 14:00 JST 24 June 1974. Ordinate: Characteristic Xray intensity in arbitrary unit.

particles containing mostly $S i$ prevailed in the air of the $0.9 \mathrm{~km}$ level over the urban area of Nagoya and there were particles with mainly $S i$ and those having the composition similar to the composition of sea water at the $0.9 \mathrm{~km}$ level over the sea south of Nagoya (Ise Bay). On electron microscopic examination of aerosol particles collected over Nagoya and Ise Bay, the aerosol consisted mainly of solid particles with irregular forms, probably soil particles.

Samples of Fig. 5a, b, c \& d were collected on a hazy summer day with windspeed less than $3 \mathrm{~m} / \mathrm{s}$ in Nagoya area. On that day, over the urban area of Nagoya, particles rich in $\mathrm{Si}$ and those rich in $S$ were predominant and those having large r.w.f. values of $S i$ and $S$ as compared with $N a$ fractions were next to them at the altitudes of 1.7 and $2.9 \mathrm{~km}$ (Fig. $5 \mathrm{a} \mathrm{\&} \mathrm{b).}$ Over the Pacific Ocean $150 \mathrm{~km}$ south of Nagoya, there were particles containing mostly $\mathrm{Si}$ and those with various r.w.f. values of $S i, N a$, and $S$ in addition to some particles having the composition similar to the composition of sea water at the $0.7 \mathrm{~km}$ level (Fig. 5c), whereas particles containing $S i$ and $S$ in large r.w.f. and $N a$ in small fractions predominated at the $2.9 \mathrm{~km}$ level (Fig. 5d). Electron micrographs of the particles collected simultaneously with the samples for electron microprobe analysis also exhibited that the aerosol consisted mainly of solid particles, and particles surrounded by a nearly circular ring of stain but without discret satellite, probably sulfate particles, not only in the air above the urban area of Nagoya, but also in the air above the sea near Nagoya. We measured the number concentration of aerosol particles larger than 


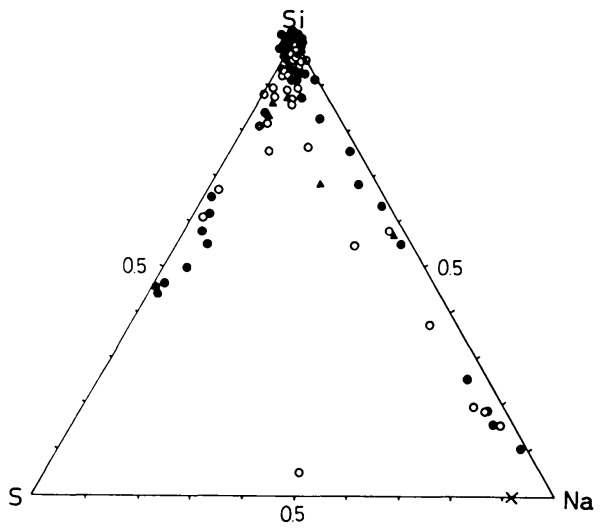

(a)

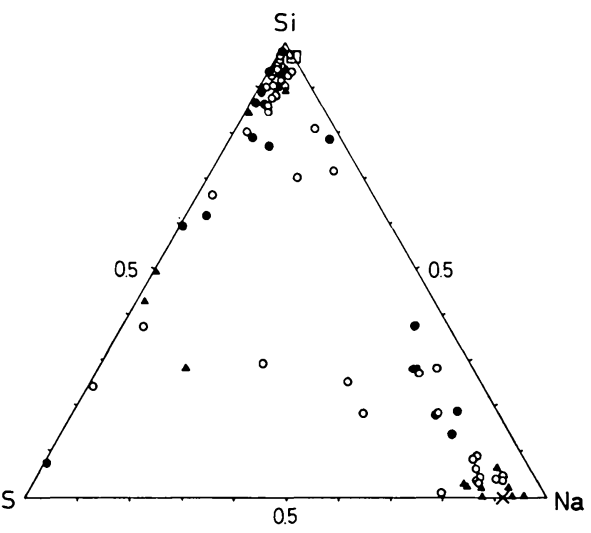

(b)

Fig. 4(a \& b) Relative weight fractions of silicon, sodium, and sulfur contained in individual aerosol particles collected at an altitude of $0.9 \mathrm{~km}$ over the urban area of Nagoya (a) and over the sea near Nagoya (b) in the period 10:00-13:00 JST 11 December 1974. $0.5-1.0 \mu \mathrm{m}, \Delta: 1.0-3.0 \mu \mathrm{m}, \bigcirc:>3.0 \mu \mathrm{m}$ in diameter, $\square$ : r.w.f. value for the composition of sedimentary rock, $x$ : r.w.f. value for the composition of sea water.

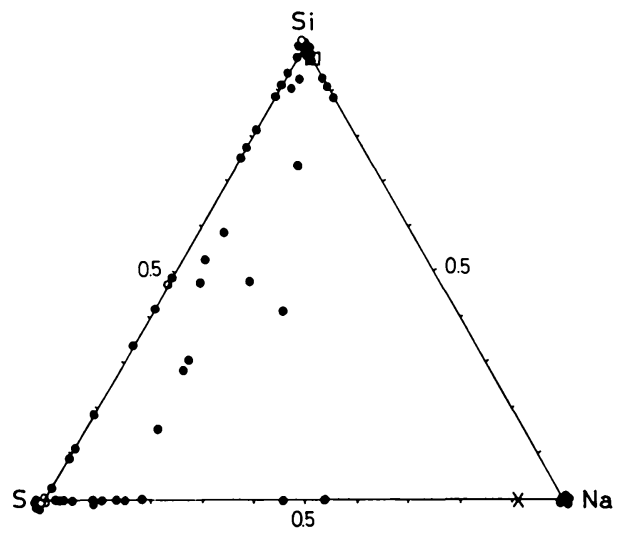

(a)

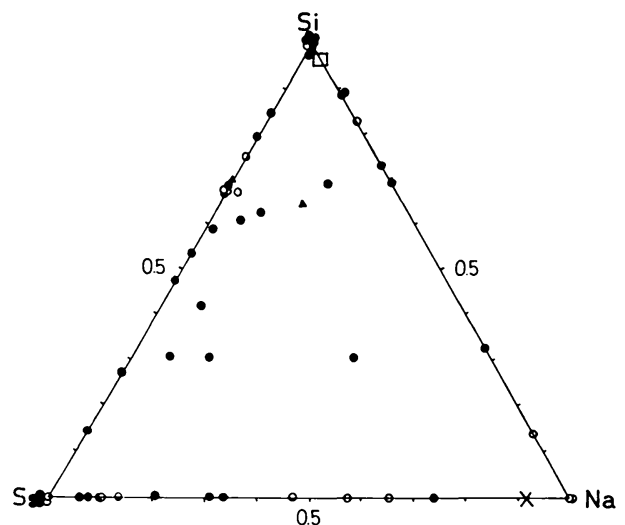

(b)

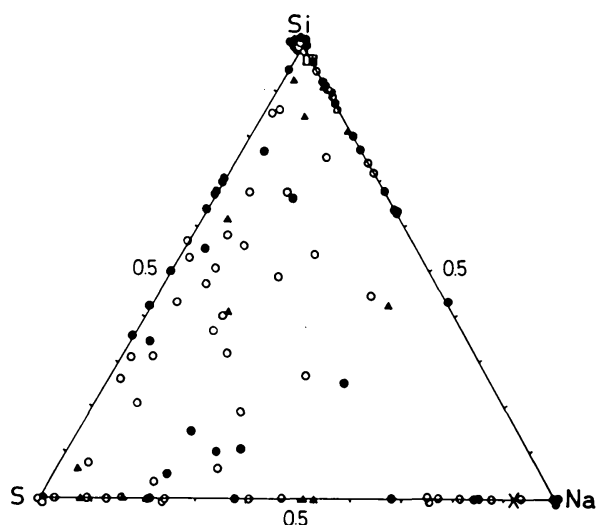

(c)

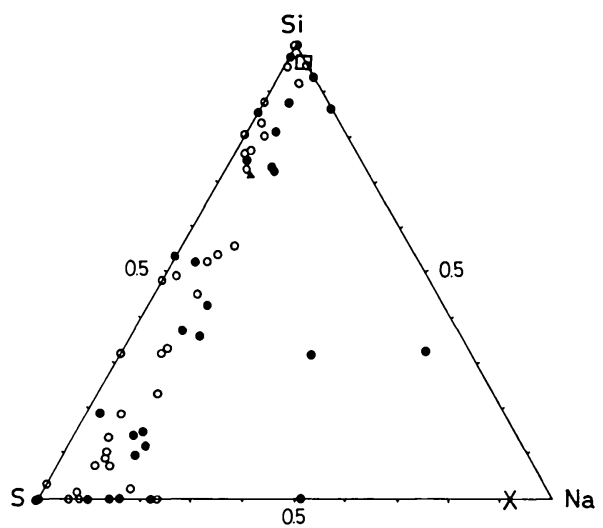

(d)

Fig. 5(a, b, c, \& d) Relative weight fractions of silicon, sodium, and sulfur contained in individual aerosol particles. Aerosol particles were collected at altitudes of $1.7 \mathrm{~km}$ (a) and $2.9 \mathrm{~km}$ (b) over the urban area of Nagoya and at altitudes of $0.7 \mathrm{~km}$ (c) and $2.9 \mathrm{~km}$ (d) over the sea near Nagoya in the period 10:30-17:00 JST 16 March 1976. Symbols are the same as in Fig. 4. 
$0.5 \mu \mathrm{m}$ in diameter using an optical particle counter (Model CI-208A, Climet) simultaneously with aerosol sampling. The measurement indicated that aerosol concentration exceeded $15 \mathrm{~cm}^{-3}$ at the $0.7 \mathrm{~km}$ level, whereas it was under $7 \mathrm{~cm}^{-3}$ above the $1.7 \mathrm{~km}$ level (Fig. 6). The depth of mixing layer above Nagoya and its vicinity can

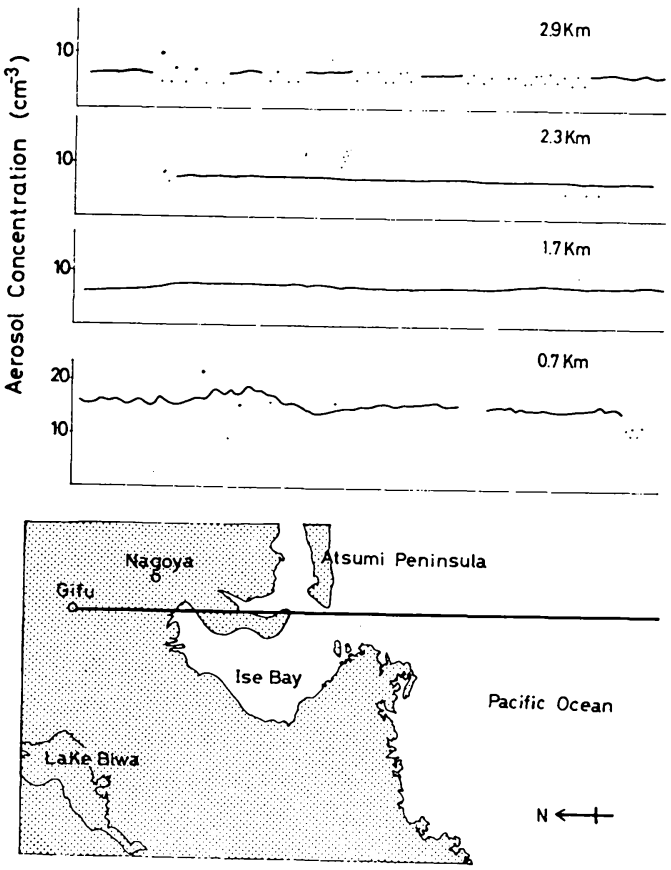

Fig. 6 Horizontal concentration profiles of aerosol particles larger than $0.5 \mu \mathrm{m}$ in diameter measured at altitudes of $0.7,1.7,2.3$, and $2.9 \mathrm{~km}$ over Nagoya area in the period 10:30-17:00 JST 16 March. Lower part shows a flight path.

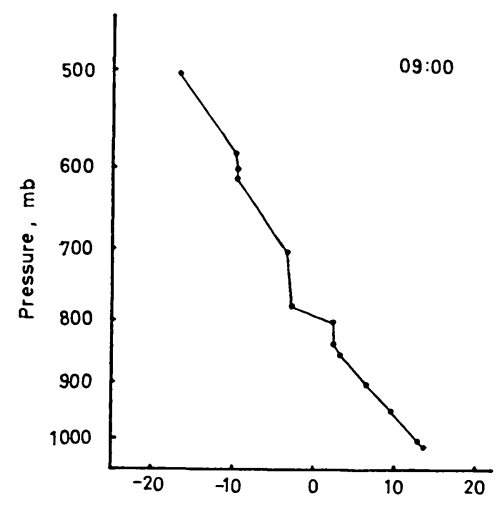

be estimated to have been lower than $1.7 \mathrm{~km}$ during sampling period from vertical aerosol concentrations and vertical temperature profiles observed at 9:00 and 21:00 JST 16 March 1976 at Hamamatsu Station, about $95 \mathrm{~km}$ south east of Nagoya (Fig. 7). Our result indicates that particles containing $S i$ and $S$ in large r.w.f. as compared with $\mathrm{Na}$ fractions prevailed in and above the mixing layer above Nagoya area on a calm day.

On the other day in summer when the wind came from the sea at Nagoya, there were particles containing $N a$ in addition to $S i$ and $S$ in large r.w.f. in the air of Nagoya (Fig. 8).

\section{(b) At the summit of Mt. Norikura}

Fig. 9a \& b shows the Si:Na:S ratios of particles collected in the afternoon and in the

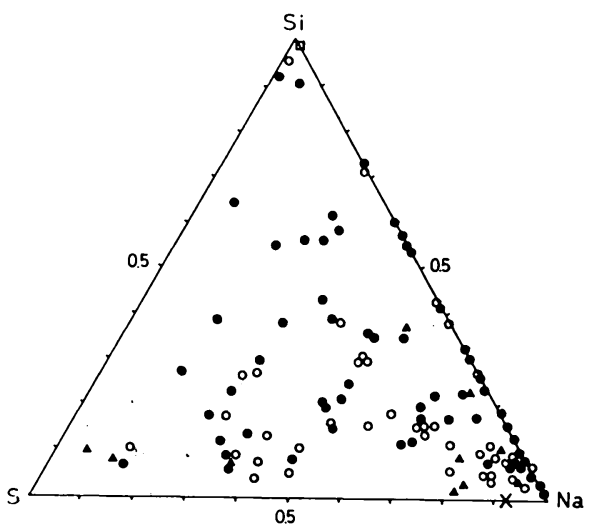

Fig. 8 Relative weight fractions of silicon, sodium, and sulfur contained in individual aerosol particles collected on the ground in Nagoya at 14:20 JST 24 June 1974.

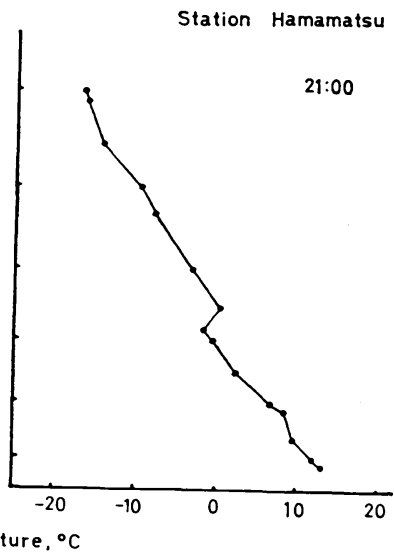

Fig. 7 Vertical temperature profiles obtained at Hamamatsu Station at 9:00 and 21:00 JST 16 March 1976. 

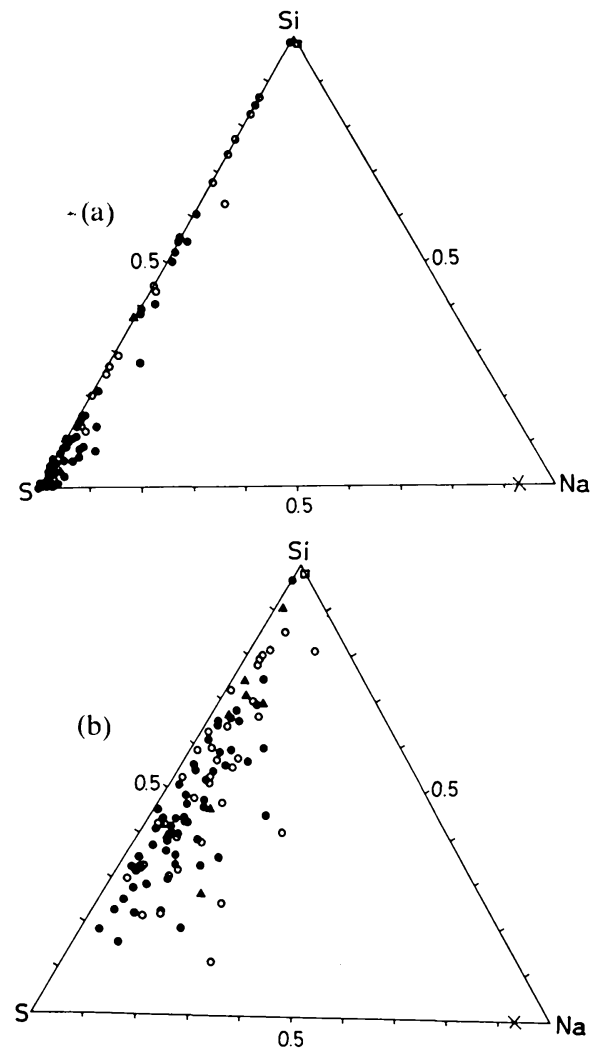

Fig. 9(a \& b) Relative weight fractions of silicon, sodium, and sulfur contained in individual aerosol particles collected at Mt. Norikura at 19:05 JST 25 (a) and at 6:43 JST 26 (b) June 1973. Symbols are the same as in Fig. 4. early morning on clear days, respectively. Relative weight fractions of $S$ and $S i$ were very large as compared with $\mathrm{Na}$ fractions, especially in the afternoon. Sulfur concentration in weight percent in individual particles larger than $1 \mu \mathrm{m}$ in diameter on those days was found to increase in the afternoon, as shown in Fig. 10. Although silicon concentration also showed a similar tendency, sodium concentration was very low and did not remarkably change with time. Fig. 11 shows time variation of number concentrations of aerosol particles larger than 0.8, 1.2, 2.0 and $4.0 \mu \mathrm{m}$ in diameter determined by optical microscopy and mixing ratios of water vapor observed at Mt. Norikura. Acrosol concentration increased in the daytime and decreased in the nighttime on those days, as is often found at the summit of the mountain (Mendonca \& Pueschel, 1972, Bigg 1977). In the nighttime on 25 June and in the early morning on 26 June 1973, Mt. Norikura was in a high pressure area. Vertical profiles of temperature and relative humidity obtained at 21:00 JST 25 June 1973 at Hamamatsu Station in the same high pressure area revealed that during this observation period a subsidence inversion was formed at an altitude of about $2.7 \mathrm{~km}$ above which the pronounced dryness was readily recognized (Fig. 12). Mixing ratios of water vapor were under $1.6 \mathrm{~g} / \mathrm{kg}$ at $1: 42$ and 8:58 JST and $7.5 \mathrm{~g} / \mathrm{kg}$ at 5:34 JST 26 June 1973. These mixing ratios of water vapor indicate that dry air subsided from upper altitudes at least between 3.0 and $4.8 \mathrm{~km}$ to the sampling site in (a)

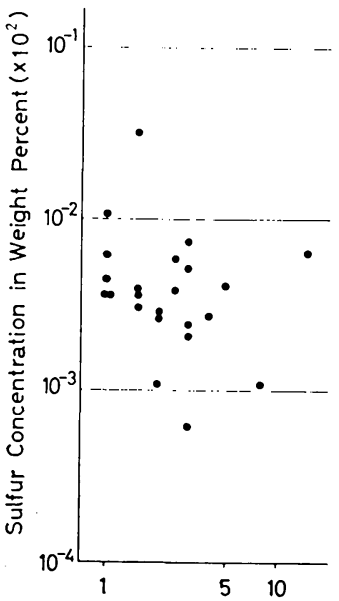

(b)

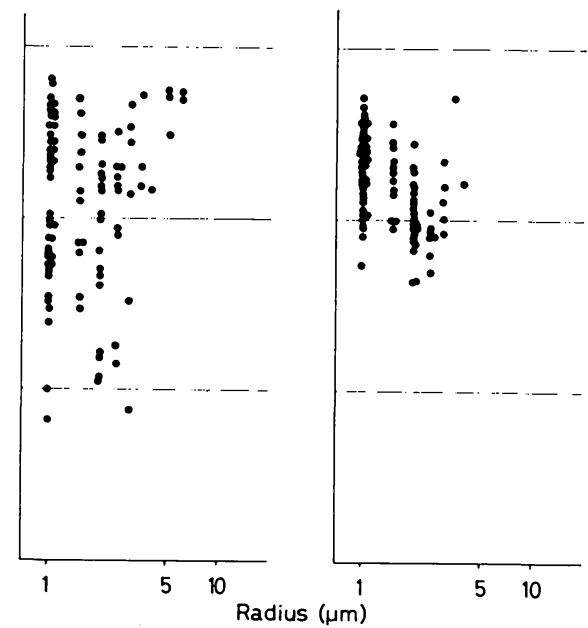

(d)

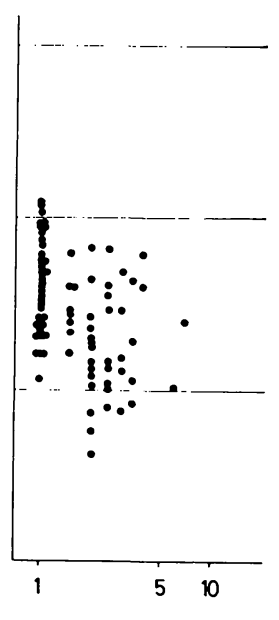

Fig. 10 Concentration in weight percent of sulfur contained in individual aerosol particles larger than $1.0 \mu \mathrm{m}$ in diameter. Aerosol particles were collected at Mt. Norikura at 6:18 (a), 13:32 (b), and 19:05 (c) JST 25 and at 6:43 (d) JST 26 June 1973. 

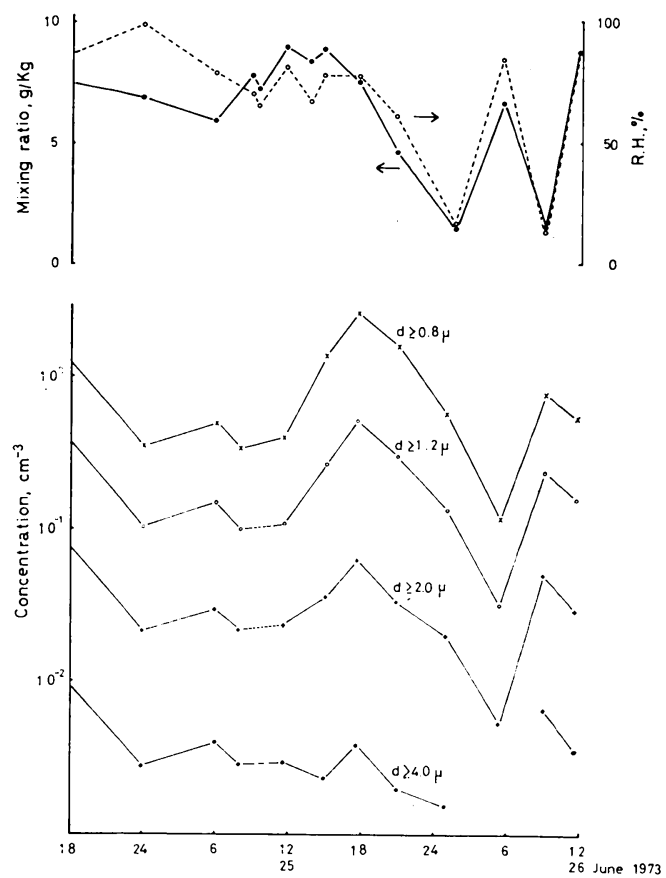

Fig. 11 Time variation of mixing ratio of water vapor (and relative humidity) and number concentration of aerosol particles larger than $0.8,1.2,2.0$, and $4.0 \mu \mathrm{m}$ in diameter observed at the summit of Mt. Norikura on 25 and 26 June 1973.

the early morning, although moist air came from lower altitudes to the site temporarily before and after 6:00 JST on that day. We collected the aerosol sample of Fig. 9b during the period of downslope flow at the site. It is to be noticed that particles containing $S$ and $S i$ in various r.w.f. prevailed during nocturnal subsidence conditions, as seen from Fig. 9b. On the other hand, the occurrence of particles rich in $S$ during afternoon was accompanied by increase in the aerosol population, as seen from Fig. 11. Simultaneous rise in the mixing ratio observed at Mt. Norikura during afternoon (Fig. 11) indicates the advection to observation site of low level sub-inversion air by convective activities. It should be emphasized that particles rich in $S$ were predominant at the time when convective activities were strong.

\section{(c) At the South Okinawa region}

Fig. 13a, b \& c shows the Si:Na:S ratios of particles collected at the altitudes of $0.6,2.1$, and $2.7 \mathrm{~km}$ on a clear day. Particles with the composition similar to the composition of sea water were predominant in the air below the
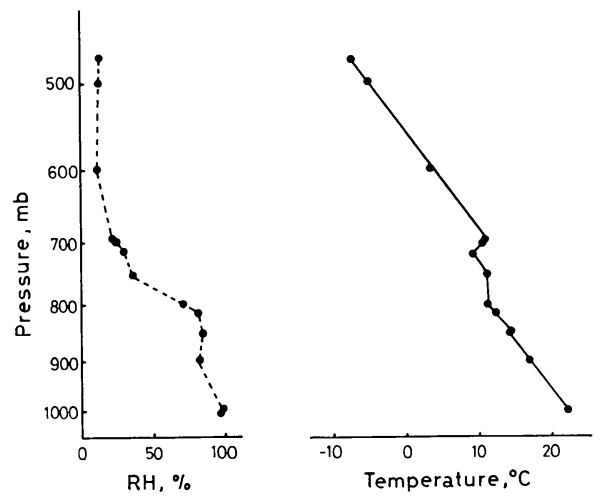

Fig. 12 Vertical profiles of temperature and relative humidity obtained at Hamamatsu Station at 21:00 JST 26 June 1973.

$1.5 \mathrm{~km}$ level, as shown in Fig. 13a. There were particles containing $S i$ and/or $S$ in large r.w.f. as compared with the composition of sea water in the air above the $2.1 \mathrm{~km}$ level, although the particles had different r.w.f. of $S i$ and $S$ at the 2.1 and $2.7 \mathrm{~km}$ levels, as shown in Fig. $13 \mathrm{~b} \& \mathrm{c}$. Fig. 14a, b \& $c$ shows the concentrations in weight percent of $S i, N a$, and $S$ contained in particles collected at the altitudes of $0.6,1.5$, 2.1 , and $2.7 \mathrm{~km}$. The figure indicates that the sodium concentration decreases rapidly with increasing altitude and decreases by factor $10^{-3}$ from 0.6 to $2.7 \mathrm{~km}$, whereas the silicon concentration increases by factor 10 from 0.6 to $2.7 \mathrm{~km}$ and sulfur concentration appears to increase slightly. The electron micrographs of formval replica of aerosol particles exhibited that particles were apparently droplets in the air below the $1.5 \mathrm{~km}$ level, whereas assumed mainly irregular forms and hemispherical forms surrounded by a circular outline without satellites in the air above the $2.1 \mathrm{~km}$ level (Fig. 15). In addition to these results, the result of relative mass increases of aerosol particles with relative humidity at 40, 70, and 90 percent indicated that the aerosol particles exhibited growth of hygroscopic particles similar to sea salt particles with relative humidity in the case of aerosol samples collected at the $0.6 \mathrm{~km}$ level, whereas they exhibited growth less than that of sea salt particles with relative humidity in the case of samples collected above the $2.1 \mathrm{~km}$ level. The depth of marine layer in the atmosphere was estimated to be about $2.0 \mathrm{~km}$ during sampling period on that day from vertical temperature pro- 


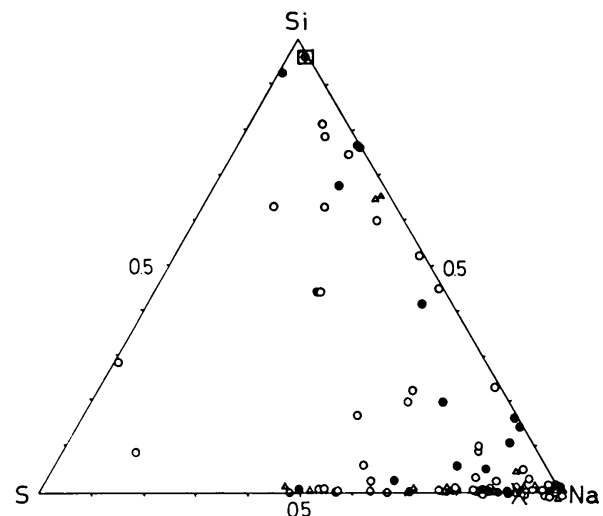

(a)

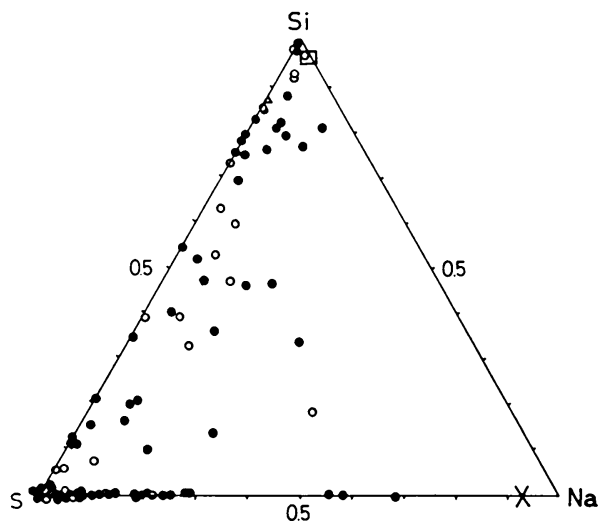

(b)

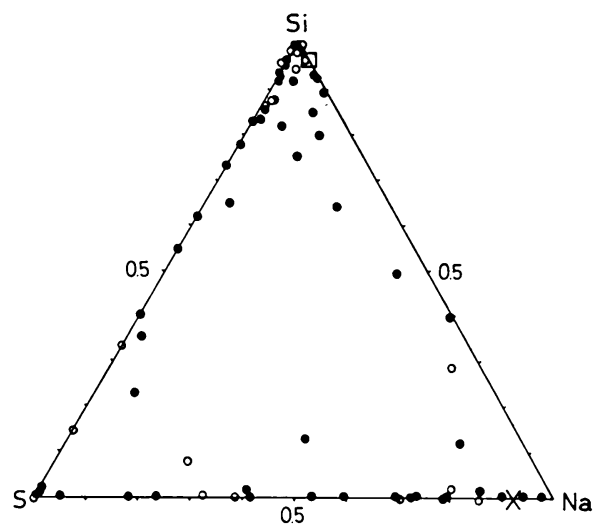

(c)

Fig. 13(a, b \& c) Relative weight fractions of silicon, sodium, and sulfur contained in individual aerosol particles. Aerosol particles were collected at altitudes of $0.6 \mathrm{~km} \mathrm{(a),} 2.1 \mathrm{~km} \mathrm{(b),} \mathrm{and} 2.7 \mathrm{~km}$ (c) over South Okinawa in the period 11:20-13:15 JST 25 February 1975. Symbols are the same as in Fig. 4. (a)

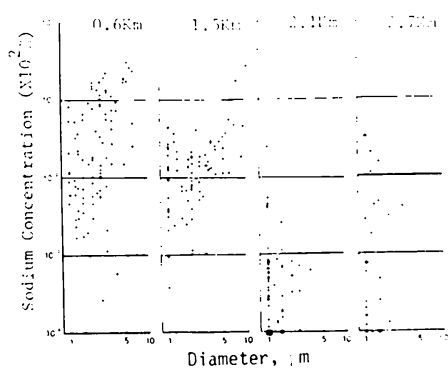

(b)

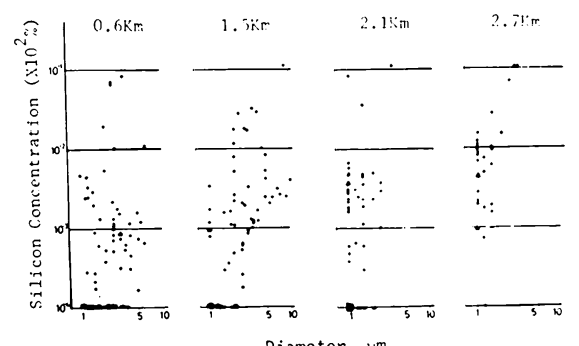

(c)

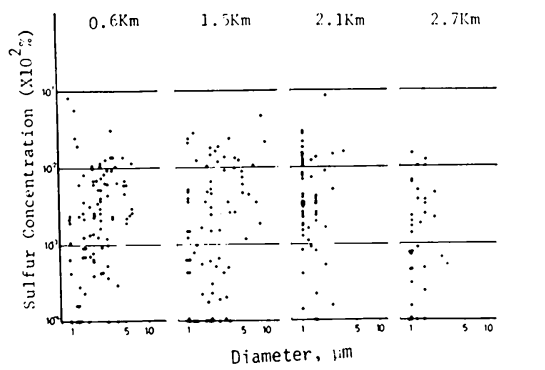

Fig. 14(a, b \& c) Concentration in weight percent of sodium (a), silicon (b), and sulfur (c) contained in individual aerosol particles larger than $1.0 \mu \mathrm{m}$ in diameter. Aerosol particles were collected at altitudes of $0.6,1.5,2.1$, and $2.7 \mathrm{~km}$ over South Okinawa in the period 11:20-13:15 JST 25 February 1975.

files observed at Miyako-jima Station. It should be emphasized that the aerosol in the marine layer consisted of particles rich in sea salt, whereas above the marine layer particles having large r.w.f. values of $S i$ and/or $S$ as compared with the composition of sea water.

\section{Discussion}

The Na:Si ratios of the average continental soil and the average continental sedimentary rock are $2.3 \times 10^{--2}$ (Vinogradov, 1959 after Delany et al., 1973). The sulfur concentration in the continental materials is very small except for Brown desert soil (Hseung \& Jackson, 1952). The value of $N a: S$ ratio in ocean water is 12.1 , 


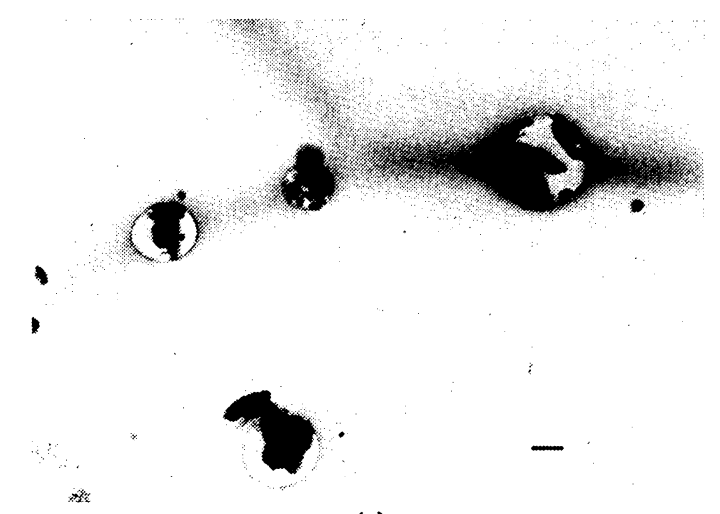

(a)

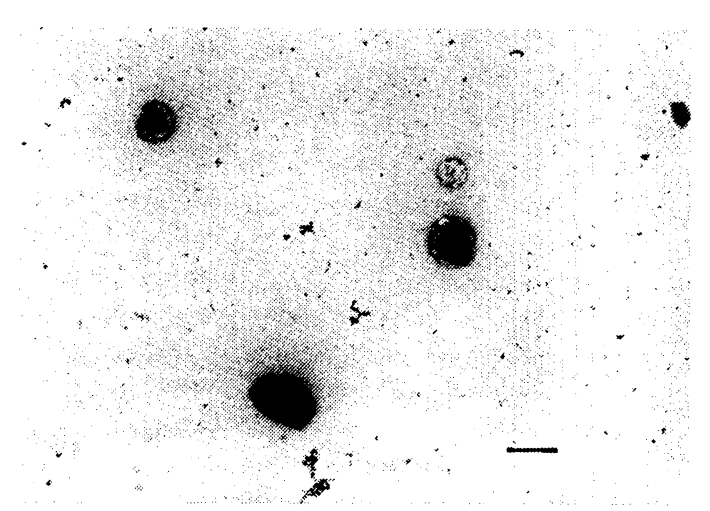

(b)

Fig. 15(a \& b) Electron micrographs of formval replica of aerosol particles collected at altitudes of $0.6 \mathrm{~km}$ (a) and $2.1 \mathrm{~km}$ (b) in the period 11:20-13:15 JST 25 February 1975. Replica was made by supplying vapor of chloroform on the formvar film on which aerosol particles were collected. (comparison scale: $1 \mu \mathrm{m}$ )

and the silicon concentration is very small (Sverdrup et al., 1961). Sulfur compounds are widely found in airborne particulate matter. By X-ray photoelectron spectroscopy, Craig et al. (1974) found that sulfur is contained in aerosols dominantly as sulfate.

The aerosol at the $0.9 \mathrm{~km}$ level over the urban area of Nagoya consisted mainly of particles rich in $\mathrm{Si}$ in the season of north west monsoon, as shown in Fig. 4a. The result of $\mathrm{X}$-ray diffraction analysis of aerosols collected in such a season in Nagoya showed that silicates were identified as quartz, feldspar, illite, kaolinite, chlorite, etc. It is reasonable to infer that particles rich in $S i$ are silicate particles. Particles having the composition close to the composition of sea water were predominant in the air up to

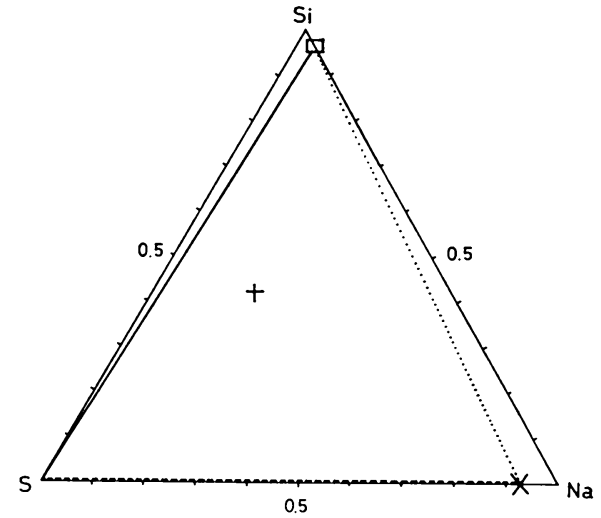

Fig. 16 Relation between position in the triangle diagram and r.w.f. of silicate, sea salt, and sulfate in individual aerosol particles. See text for further explanation.

$1.5 \mathrm{~km}$ over the ocean of South Okinawa, as shown in Fig. 13a. Many particles collected above the urban area of Nagoya on a calm day contained sulfur in large r.w.f. as compared with the composition of continental materials and sea water, as seen from Fig. 5a. Therefore, the $S i: N a: S$ ratios of individual particles can reflect the relative contribution of silicate, sea salt, and sulfate components contained in particles.

We showed the Si:Na:S ratios of individual particles in triangle diagrams such as Fig. 16. From the positions in the triangle diagrams, we can easily estimate r.w.f. of silicate, sea salt, and sulfate contained in individual particles. Positions in the diagrams are related to r.w.f. of silicate, sea salt, and sulfate in particles as follows: Particles locating in the positions close to open rectangle (For example, Fig. 4a \& b), cross (Fig. 13a) and $S$ (Fig. 5a) in the diagrams mean to be those rich in silicate, sea salt, and sulfate, respectively. Particles locating in the positions close to full line (Fig. 5b, 9b, and 13c), dotted line (Fig. 4b) and dashed line (Figs. 5c and 13a) shown in Fig. 16 mean to be mixed particles containing silicate and sulfate, silicate and sea salt, and sulfate and sea salt in various r.w.f., respectively. Particles locating in the positions such as plus sign shown in Fig. 16 (Figs. 5c and 13b) mean to be mixed particles containing silicate, sea salt, and sulfate in large r.w.f.

It is known that continental soil comes from the arid or semi-arid regions of the Asian Continent to over Japan in the season of north west monsoon (Ishizaka, 1972, 1973). The elemental composition of individual particles col- 


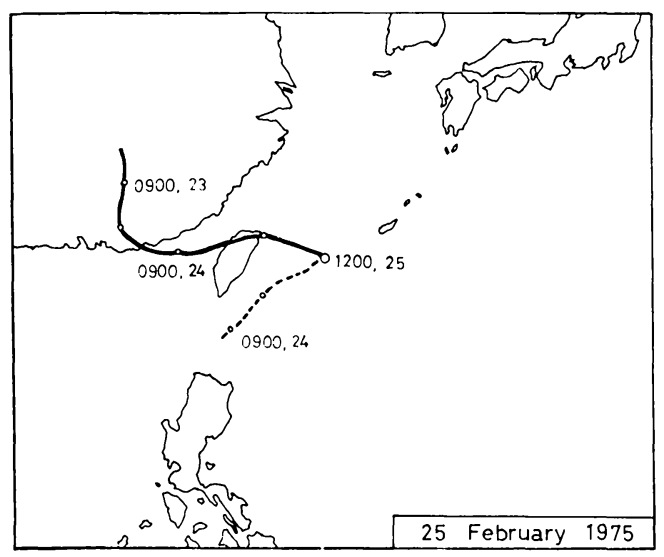

Fig. 17 Trajectories of air masses for 12:00 JST 25 February 1975. ...... $850 \mathrm{mb}$, —: $700 \mathrm{mb}$.

lected in the air above Nagoya and its vicinity in such a season (Fig. 4a \& b) can be explained by pure soil particles, as expected naturally. Silicate component often formed an important part in the large particles $(d \geq 0.5 \mu \mathrm{m})$ collected in the air above Nagoya and its vicinity on other days. On a calm day in spring, the aerosol consisted mainly of mixed particles containing silicate and/ or sulfate in the large r.w.f. and sea salt in small fractions except the aerosol in the marine layer above the sea near Nagoya, as can be seen from Fig. 5a, b, c \& d. A large contribution of silicate component to individual particles were found not only in the air above around Nagoya, but also in the air over the South Okinawa region. At the $2.7 \mathrm{~km}$ level over the South Okinawa region, silicate component imposed heavier burden on individual particles and consequently particles rich in silicate were predominant, as can be seen from Figs. $13 \mathrm{c}$ and $14 \mathrm{~b}$. In order to examine the main source region of silicates in these particles over the South Okinawa region, trajectories of air masses which arrived at the region at 12:00 JST 25 February 1975 were traced back along 700 and $850 \mathrm{mb}$ surfaces through several 12-hr periods (Fig. 17). The air mass at the $700 \mathrm{mb}$ level came from South China and Taiwan. The South China Continent is known to be one of the main source regions of atmospheric soil particles observed around Japan (Ishizaka, 1972, 1973). Therefore, silicates contained in the particles over the South Okinawa region may be originated from the South China Continent. From the result described above, we can point out that continental-derived silicate had a fairly wide-spread distribution in the air around the Japanese Islands.

Sulfate component made a contribution as large as silicate component to the large particles $(d \geq 0.5 \mu \mathrm{m})$ in the air above the urban area of Nagoya on a calm day, as can be scen from Fig. $5 \mathrm{a}, \mathrm{b}, \mathrm{c} \& \mathrm{~d}$. The unpublished data of bulk chemical composition of aerosol particles $(d \geq$ about $0.5 \mu \mathrm{m}$ ) collected at Nagoya by the authors also indicated that sulfate concentration exceeded $20 \mu \mathrm{g} / \mathrm{m}^{3}$ on calm days in spring and summer. Nakai (1975) made isotopical analysis of sulfur in rain water to determine the source regions of atmospheric sulfur and found that $\delta^{34} S$ values of sulfate in rain water collected at Nagoya in 1973 are -1.0 to +2.7 per mill lighter than that of sea water sulfate. He estimated that about 75 weight percent of sulfate in rain water are of industrial and other anthropogenic origins. Sulfate made a great contribution to the afternoon particles at Mt. Norikura as compared with the particles in the urban area of Nagoya, as can be seen from Fig. 9a. As described in the preceding section, the afternoon particles are inferred to be brought from lower altitudes to the observation site by diurnal heating in the daytime. It is well known that the air of the rural areas in the Chubu district is polluted by sulfur dioxide due to anthropogenic emissions in Japan (Ambient Air Quality in Japan, 1975). While sulfur dioxide in the lower atmosphere is brought to the observation site in the daytime, a part of sulfur dioxide will be oxidized either photochemically or catalytically and contribute to the increase of sulfate content of large particles $(d \geq 0.5 \mu \mathrm{m})$. It might be, therefore, nothing wonderful that the particles rich in sulfate werc predominant at the summit of Mt. Norikura in the afternoon on clear days. It is an important finding that sulfate concentration in individual particles increased and consequently particles rich in sulfate prevailed at Mt. Norikura at the time when convective activities were strong in the daytime (Fig. 9a and 10). Over the South Okinawa region, although relative contribution of silicate, sea salt, and sulfate contained in individual particles changed with altitude, sulfate concentration in the particles appeared to increase with increasing altitude (Fig. 14) and r.w.f. of sulfate in the particles were large as compared with the composition of sea water, especially at altitudes higher than $2.1 \mathrm{~km}$ (Fig. $13 \mathrm{a}, \mathrm{b} \& \mathrm{c})$. Recent investigation by Gravenhorst (1978) into the composition of sulfate-aerosols in 
the unpolluted air over ocean have shown that the sulfate concentration of the acrosols in the marine air always in excess as compared with the sulfate content of ocean water. Hoffman et al. (1974) revealed that sulfate is not enriched in the sea salt particles with respect to sea water but that higher concentration could be caused by advection from the continent. As seen from Fig. 17, the air masses of about $700 \mathrm{mb}$ level over the South Okinawa region came directly from Taiwan and South China. The excess sulfate might, therefore, be transported from the land, such as Taiwan and South China, or formed over the ocean within the atmosphere. It is likely that sulfate component not of marine origin also makes a large contribution to the particles in the air around the Japanese Islands.

Particles rich in sea salt were often found in the air below about $2.0 \mathrm{~km}$ level in the sea near Nagoya and in the South Okinawa region, as can be seen from Figs. 5c and 13a. However, they could be hardly detected in the air above about $2.0 \mathrm{~km}$ level in their regions, as can be seen from Figs. 5b \& d and 13b. Furthermore, sea salt component made only a very small contribution to individual particles in the air of Mt. Norikura, as can be scen from Fig. 9a \& b. These results suggested that many sea salt particles do not penetrate upward to altitudes higher than about $2.0 \mathrm{~km}$ and far inland, as pointed out by some workers (Junge et al., 1969; Dinger et al., 1970; Gillette \& Blifford, 1971; Delany et al., 1973).

As a result described above, the particles in the airs above the mixing layer around Nagoya and above the marine layer around the South Okinawa region were found to have a tendency to contain silicate and/or sulfate in large r.w.f. as compared with sea salt fractions, as can be seen from Figs. $5 b \& d$ and $13 b \&$ c. The composition of the aerosols in the troposphere has been examined by some workers such as Gillette \& Blifford (1971), Simpson (1972), Delany et al. (1973) and Cattell et al. (1977). Gillette \& Blifford (1971) examined bulk samples of aerosols collected up to $9 \mathrm{~km}$ over California (Death Valley), Nebraska and the Pacific offshore with $\mathrm{X}$-ray fluorescence spectroscopy and suggested that the soil component of the aerosol is quite constant with respect to altitude and location and sea salt component makes a small contribution at the higher altitudes. They also found that sulfate- $S$ of the aerosol may be at least partly due to anthropogenic emissions. Delany et al. (1973) made instrumental neutron activation analysis of aerosols collected simultaneously with Gillette et al.'s collection on aircraft flights and found that the aerosol in the troposphere is a uniform aerosol composed of 90-95 parts continental material and 5-10 parts marine material. As pointed out by them, the early morning particles at Mt. Norikura, which were originated possibly from the middle troposphere, contained silicate and sulfate in large r.w.f. and sea salt in very small fractions. However, a very important fact can be drawn by careful analysis of Figs. $5 b$ \& d, $9 b$ and $13 b$ \& c. The elemental composition of the particles in the free atmosphere can be explained chiefly by mixed particles containing silicate and sulfate in large r.w.f. and sea salt in very small fractions. This strongly suggests that aerosol particles $(d \geq 0.5 \mu \mathrm{m})$ in the free atmosphere over the Japanese islands may consist mainly of mixed particles containing silicate and sulfate in large r.w.f. and sea salt in a minor constituent.

\section{Conclusion}

The following results can be estimated from the elemental analysis for silicon, sodium, and sulfur contained in individual aerosol particles larger than $0.5 \mu \mathrm{m}$ in diameter (at 0 percent relative humidity):

(1) Over Nagoya and its vicinity, the acrosol consisted often of particles containing silicate and/or sulfate in large r.w.f. as compared with sea salt fractions in and above the mixing layer.

(2) At the summit of Mt. Norikura, particles rich in sulfate were predominant when convective activities were strong, whereas mixed particles having large r.w.f. values of silicate and sulfate as compared with sea salt fractions during nocturnal subsidence conditions.

(3) Over the South Okinawa region, two regimes were clearly delineated: The aerosol consisted mainly of particles rich in sea salt in the marine layer, whereas particles which contain silicate and/or sulfate in large r.w.f. as compared with the composition of sea water above the marine layer.

The results described above have indicated that the composition of individual particles in the mixing layer (its depth is about $2.0 \mathrm{~km}$ ) depends strongly on location: Over the urban area of Nagoya and its vicinity, the aerosol consists mainly of particles rich in silicate and/or sulfate and, over the ocean, of particles rich in sea salt, whereas the aerosol above the mixing layer consists mainly of mixed particles which 
contain silicate and/or sulfate in large r.w.f. and sea salt in a minor constituent regardless of location. Although there is at present insufficient data which to base a conclusion, we believe that mixed large particles $(d \geq 0.5 \mu \mathrm{m})$ having large r.w.f. values of silicate and sulfate as compared with sea salt fractions distribute widely in the free atmosphere over the Japanese Islands from Honshu to Okinawa.

Electron microprobe analysis is a very useful method for detection of trace elements contained in individual aerosol particles. However, we could not quantitatively examine the elemental composition of individual particles smaller than $0.5 \mu \mathrm{m}$ in diameter, because characteristic $\mathrm{X}$-ray intensities of elements contained in their particles were very low. Furthermore, the aerosol in the troposphere must consist often of mixed particles which contain various materials, such as silicate, sulfate, hydrocarbon and nitrogen compounds. Further extensive study is very necessary to determine the material composition of individual particles in the troposphere in more detail.

\section{Acknowledgements}

The authors wish to express their sincere thanks to Dr. Y. Tsuzuki and Mr. Y. Yusa, Faculty of Science, Nagoya University, for helpful discussion on analysis of individual aerosol particles with an electron microprobe. They are indebted to Mr. K. Okada, Water Research Institute, Nagoya University, who measured number concentration of aerosol particles collected at the summit of Mt. Norikura. They wish to express their thanks to Prof. A. Ono, Water Research Institute, for reviewing of the manuscript. They are also indebted to staff members of Cosmic Ray Observatory, Tokyo University, and the radar observation group of the Meteorological Research Institute for their efforts in collecting the samples. This study was supported by a Fund for Scientific Research from the Ministry of Education.

\section{Appendix}

We shall herein describe the method of quantitative microprobe analysis of individual aerosol particles employed throughout the present study in brief (Ishizaka et al., 1976 for details).

The concentration in weight percent of element $A$ in individual particles of diameter $d, C_{d}{ }^{A}$, can be approximately expressed as follows,

$$
C_{d}{ }^{\wedge} \fallingdotseq 100 \cdot K_{d}^{A} \cdot V_{d}^{A} \cdot A_{d}^{A}
$$

where $K_{d}{ }^{A}$ is the background-corrected intensity ratio of a characteristic radiation line of element $A$ present in a particle of diameter $d$ relative to that of pure $A$ with flat surface, $V_{d}{ }^{A}$ the X-ray emitting volume ratio of a characteristic line of element $A$ in the particle relative to that of pure $A$ with flat surface, and $A_{d}{ }^{A}$ the correction factor except X-ray emitting volume factor for the particle.

In order to determine the concentration in weight percent of element $A$ in the particle exactly, correction factor $\beta_{d}{ }^{A}$ defined by the equation (A5) must be multiplied to the right side of equation (A1). However, we herein ignored this factor.

Using equation (A1), weight concentration ratio of element $A$ relative to $B$ present in the particle is given by

$$
\frac{C_{d}{ }^{A}}{C_{d^{B}}{ }^{B}} \fallingdotseq \frac{K_{d}{ }^{A}}{K_{d}{ }^{B}} \cdot \frac{V_{d}^{A}}{V_{d}^{B}} \cdot \frac{A_{d}^{A}}{A_{d}^{B}}
$$

As will be described later, $V_{d}{ }^{A}$ and $A_{d}{ }^{A}$ are hardly dependent on element species in the case of the same particle. Therefore, equation (A2) is rewritten as follows,

$$
\frac{C_{d}{ }^{A}}{C_{d^{B}}} \fallingdotseq \frac{K_{d}{ }^{A}}{K_{d}{ }^{B}}
$$

Where pure $A$ or $B$ is not available as standard, other working standards (oxides) may be used to obtain $K_{d}{ }^{A} . K_{d}{ }^{A}$ is given by

$$
K_{d}^{A}=\frac{k_{d}^{A}}{k_{p}{ }^{A}}=\frac{k_{d}^{A}}{k_{d}^{A}} \cdot C_{w s}^{A}
$$

where $k_{d}{ }^{A}$ is the background-corrected intensity of a characteristic line of element $A$ in the particle, $k_{p}{ }^{A}$ the background-corrected intensity of a characteristic line of element $A$ in the case of pure $A$ with flat surface, $k_{w s}{ }^{A}$ the backgroundcorrected intensity of a characteristic line of element $A$ in working standard with flat surface, $C_{w s}{ }^{A}$ the concentration in weight percent of element $A$ in working standard, and $\beta_{w s}{ }^{A}$ is defined as

$$
\beta_{w s}{ }^{A}=\alpha_{A}^{A} \cdot C_{A}+\alpha_{B}^{A} \cdot C_{B}+\cdots+\alpha_{N}^{A} \cdot C_{N}
$$

where $\alpha_{B}{ }^{A}$ is the parameter for $A$ radiation in element $B$ (For $\alpha_{B}{ }^{A}>1$, absorption dominates, and for $\alpha_{B}{ }^{A}<1$, fluorescence dominates in the matrix effects. Please refer to related papers such as Bence \& Albee, 1968 for details.) The $\beta_{w s}{ }^{A}$ factor was calculated using $\alpha$-factor for element transformed from $\alpha$-factor for the pure oxide (Yusa \& Tsuzuki, 1976). 


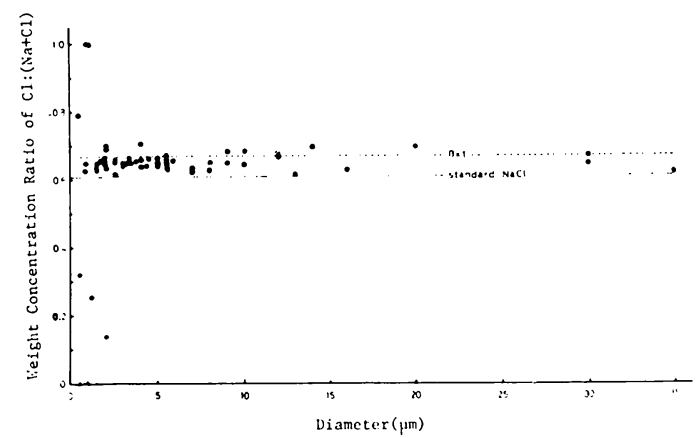

Fig. A1 Weight concentration ratio of $\mathrm{Cl}:(\mathrm{Na}+$ $C l$ ) in sodium chloride particles obtained using equation (A6). - exact value for sodium chloride particles, -...-: theoretical value for sodium chloride particles in the case of $\beta=1$.

Equation (A3) is rewritten as

$$
\frac{C_{d}^{A}}{C_{d}{ }^{B}}=\frac{k_{d}^{A}}{k_{d}{ }^{B}} \cdot \frac{k_{p}{ }^{B}}{k_{p}{ }^{A}}
$$

The background-corrected intensity ratio $\left(k_{p}{ }^{A} /\right.$ $k_{p}{ }^{B}$ ) of a characteristic line of pure $A$ relative to that of pure $B$ with flat surface is clearly constant. Hence equation (A6) reveals that the relative weight fractions of element $A$ and $B$ present in the particle is approximately proportional to the background-corrected intensity ratio of element $A$ to $B$ present in the particle. Fig. A1 shows the weight concentration ratios of chlorine to sodium and chlorine in sodium chloride particles obtaincd using equation (A6). As is seen from Fig. A1, it is often possible to determine relative weight fractions of element $A$ and $B$ in individual particles larger than size of $0.5 \mu \mathrm{m}$ in diameter at most to \pm 10 percent of practical values. The experimental result of White et al. (White, 1964; White et al., 1969) supports the idea that equation (A6) is applicable to determination of the relative weight fractions of element $A$ and $B$ present in a particle. On the other hand, $V_{d}{ }^{A}$ is defined as

$$
V_{d}^{A}=\frac{V_{A}}{v_{d}^{A}}
$$

where $v_{d}{ }^{A}$ and $V^{A}$ are the $\mathrm{X}$-ray emitting volume of a characteristic line of element $A$ in the particle of diameter $d$ and that of pure $A$ with flat surface, respectively.

If the diameter of cross section of the electron diffusion zone in pure $A$ with flat surface is $B$ and the depth of the electron diffusion zone in pure $A$ with flat surface and in the particle is $h$ (Fig. A2), the X-ray emitting volume ratio $V_{d}{ }^{A}$ of a characteristic line of element $A$ in the

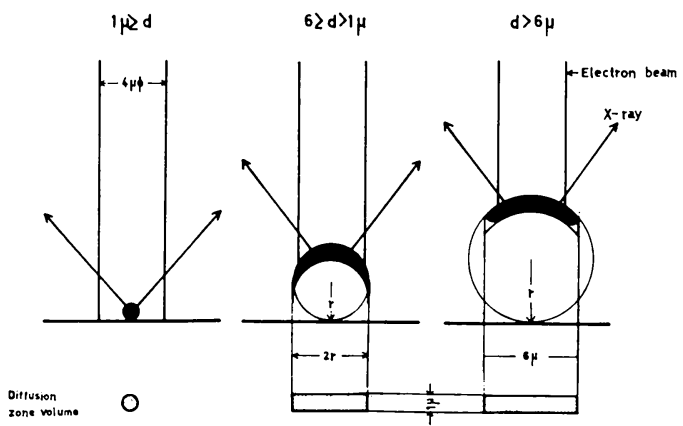

Fig. A2 Electron diffusion zone in spherical particle shown schematically. B: diameter of cross section of electron diffusion zone in standard element with plane surface, $h$ : depth of electron diffusion zone in standard element and in particle.

particle relative to that of pure $A$ with flat surface can be deduced as follows:

(i) in the case of $B>h \geq d$

$$
V_{d}^{A}=V_{d}=\frac{2}{3} \cdot \frac{B^{2} h}{d^{3}}
$$

(ii) in the case of $B \geq d>h$

$$
V_{d}^{A}=V_{d}=\frac{B^{2}}{d^{2}}
$$

(iii) in the case of $d>B>h$

$$
V_{d}{ }^{A}=V_{d}=1
$$

$h$ is generally dependent on the operating voltage and average atomic weight and atomic number of analyzing material. As operating voltage is $15 \mathrm{kV}$ and average atomic number of aerosol particles is almost constant, which is about 13 , we put $1 \mu \mathrm{m}$ for $h$ (Uchiyama et al., 1974). We shall be able to put $6 \mu \mathrm{m}$ for $B$, because the background-corrected intensity of a characteristic line of element $A$ in the particles was almost constant for particles larger than about $6 \mu \mathrm{m}$ in diameter.

$A_{d}{ }^{A}$ could not be expressed by a simple equation. Therefore, $A_{d}{ }^{N a}$ was determined by substituting $C_{d}^{N a}, K_{d}^{N a}$, and $V_{d}$ into equation (A1), as equation (A1) holds at various particle sizes. $K_{d}{ }^{N a}$ was obtained from the backgroundcorrected average intensity of a characteristic radiation of sodium present in particles of diameter $d$ and $V_{d}^{N a}$ from equation (A8), (A9), or (A10). As a result of investigating many data, $A_{d}{ }^{N a}$ was found to be given by

$$
\frac{1}{A_{d} \mathrm{Na}}=0.20 d^{2}-2.43 d+8.18
$$

Fig. A3 shows sodium concentration in weight 


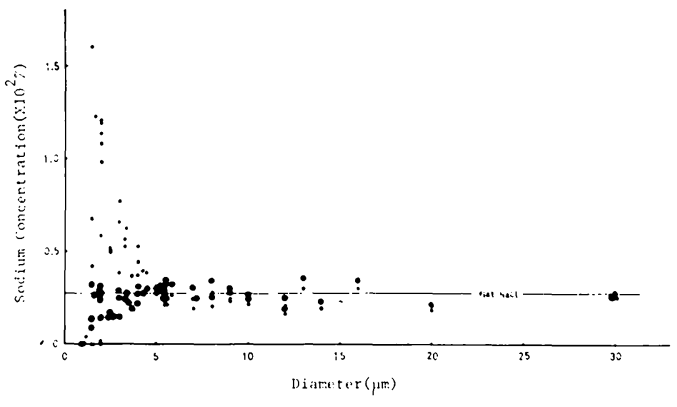

Fig. A3 Concentration in weight percent of sodium in sodium chloride particles calculated from the background-corrected intensities of a characteristic radiation of sodium present in the particles. $\bullet:$ values corrected only for electron diffusion zone of particles, -: values fitted to theoretical values for sodium in sodium chloride particles, flat $\mathrm{NaCl}$ : experimental value for rock-salt with plane surface.

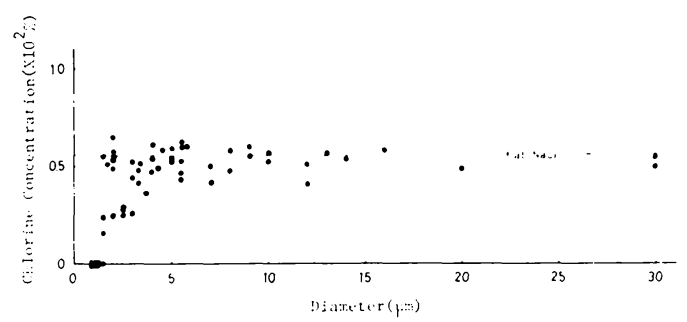

Fig. A4 Concentration in weight percent of chlorine in sodium chloride particles calculated from $K_{d} C l, V_{d}$, and $A_{d}{ }^{N a}$. Flat $\mathrm{NaCl}$ is the same as in Fig. A3.

percent in sodium chloride particles detcrmined from $K_{d}{ }^{N a}$. We attempted to calculate $C_{d}{ }^{C l}$ by substituting $K_{d}^{C l}, V_{d}$ and $A_{d}{ }^{N a}$ into equation (A1) (Fig. A4). $\quad K_{d}^{C l}$ was obtained from the background-corrected intensity of a characteristic radiation of chlorine present in a particle of diameter $d$. Fig. A4 indicates chlorine concentration in weight percent in sodium chloride particles. This fact suggests that $A_{d}{ }^{C l}$ is approximately given by equation (A11) and hardly dependent on element species in the case of the same particles. Therefore, it is sufficiently accurate for our purposes to assume that the concentration in weight percent of element $A$ in individual particles is given by

$$
C_{d}^{A}=100 \cdot K_{d}^{A} \cdot V_{d} \cdot A_{d}
$$

\section{References}

Ambient Air Quality in Japan-In fiscal year 1974, 1975, edited by Air Pollution Control Division, Air Quality Bureau, Environment Agency.
Gyosei Co., Ltd., Tokyo, pp. 1570 (In Japanese). Bence, A. E., and A. L. Albee, 1968: Empirical correction factors for the electron microanalysis of silicate and oxides. J. Geol., 76, 382-403.

Bigg, E. K., 1977: Some properties of the aerosol at Mauna Loa Observatory. J. Appl. Meteor., 16, 262-267.

Bodhaine, B. A., and R. F. Pueschel, 1972: Flame photometric analysis of the transport of sea salt particles. J. Geophys. Res., 7\%, 5106-5115.

Cadle, R. D., R. Bleck, J. P. Shedlovsky, I. H. Blifford, J. Rosinski, and A. L. Lazrus, 1969: Trace constituents in the vicinity of jet streams. $J$. Appl. Meteor., 8, 348-356.

Cattell, F. C. R., W. D. Scott, and D. du Cros, 1977: Chemical composition of aerosol particles greater than $1 \mu \mathrm{m}$ diameter in the vicinity of Tasmania. J. Geophys. Res., 82, 3457-3462.

Craig, N. L., A. B. Harker, and T. Novakov, 1974: Determination of the chemical states of sulfur in ambient pollution aerosols by X-ray photoelectron spectroscopy. Atmos. Env., 8, 15-21.

Delany, A. C., W. H. Pollock, and J. P. Shedlovsky, 1973: Tropospheric aerosol: The relative contribution of marine and continental components. J. Geophys. Res., 78, 6249-6265.

Dinger, J. E., H. B. Howell, and T. A. Wojciechowski, 1970: On the source and composition of cloud nuclei in a subsident air mass over the North Atlantic. J. Atmos. Sci., 27, 791-797.

Georgii, H. W., and W. Vitze, 1971: Global and regional distribution of sulfur components in the atmosphere. Idörajas, 5-6, 294-299.

Gillette, D. A., and I. H. Blifford, 1971: Composition of tropospheric aerosols as a function of altitude. J. Atmos. Sci., 28, 1199-1210.

Gravenhorst, G., 1978: Maritime sulfate over the North Atlantic. Atmos. Env., 12, 707-713.

Hoffman, E. J., G. L. Hoffman, and R. Duce, 1974: Chemical fractionation of alkali and alkaline earth metals in atmospheric particulate matter over the North Atlantic. J. Rech. Atmos., 8, $675-688$.

Hseung, Y., and M. L. Jackson, 1952: Mineral composition of the clay fraction: III. of some main soil groups of China. Soil Sci. Soc. Amer. Proc., 16, 294-297.

Ishizaka, Y., 1972: On materials of solid particles contained in snow and rain water: Part $1 . J$. Meteor. Soc. Japan, 50, 362-375.

1973: On matcrials of solid particles contained in snow and rain water: Part 2. J. Meteor. Soc. Japan, 51, 325-336.

-, Y. Yusa, and Y. Tsuzuki, 1976: Quantitative analysis of elements in aerosol by means of electron probe microanalyser. J. Min. Soc. Japan, 12, (Special Issue), 230-239 (In Japanese).

Junge, C. E., E. Robinson, and F. L. Ludwig, 1969: A study of aerosols in Pacific Air Masses. $J$. 
Appl. Meteor., 8, 340-347.

Mendonca, B. G., and R. F. Pueschel, 1973: Ice nuclei, total aerosol, and climatology at Mauna Loa, Hawaii. J. Appl. Meteor., 12, 156-160.

Nakai, N., N. Takahashi, and U. Takeuchi, 1975: Sources of sulfate in rain water and air pollution. Geochemistry (Chikyukagaku), (Special Issue), 118-124 (in Japanese).

Ono, A., 1978: Sulfuric acid particles in subsiding air over Japan. Atmos. Env., 12, 753-757.

Ranz, W. G., and J. B. Wong, 1952: Impaction of dust and smoke particles. Ind. Eng. Chem., 44, 1371-1381.

Simpson, H. J., 1972: Aerosol cations at Mauna Loa Observatory. J. Geophys. Res., 77, 5266-5277.

Sverdrup, H. V., M. W. Johnson, and R. H. Fleming, 1961: Chemistry of Sea Water (Chapter VI). The
Oceans, Prentice-Hall/Tuttle, Tokyo, 165-227.

Uchiyama, I., A. Watanabe, and S. Kimoto, 1974: Electron probe X-ray microanalyser. NitsukanKogyo Shinbunsha, Tokyo, pp. 243 (in Japanese). White, E. W., 1964: Microprobe technique for the analysis of multiphase microcrystalline powders. Amer. Min., 49, 196-197.

P. L. Denny, and S. M. Irving, 1969: Quantitative microprobe analysis of Microcrystalline powders. The Electron Microscope (Edited by T.D. Mcknley et al.), John Willey and Sons, New York, 791-804.

Yusa, Y., and Y. Tsuzuki, 1976: Mutual transformation among $\alpha$-factors for elements, oxides and some minerals. J. Min. Soc. Japan, 12, (Special Issue), 93-100 (in Japanese).

\title{
対流圏下部のエアロゾル粒子 1 個 1 個の物質組成に関する $\mathrm{X}$ 線分析法による研究
}

\author{
石 坂隆・礒 野 謙 治 \\ 名古展大学水圈科学研究所
}

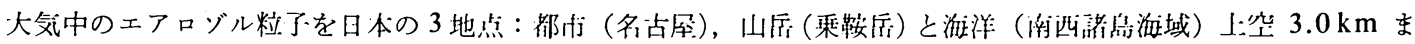

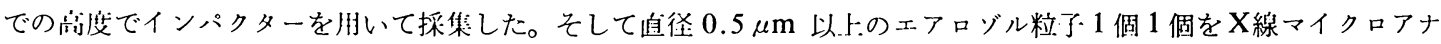

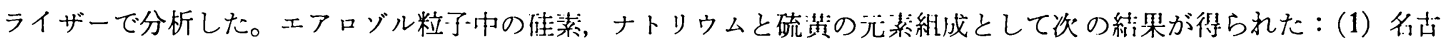

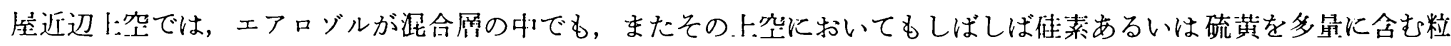
子から成っていた。（2）乘鞍孚の山頁では，日芷の対流活動の活発な時にはエアロゾルが硫黄を多昂に含む粒子から

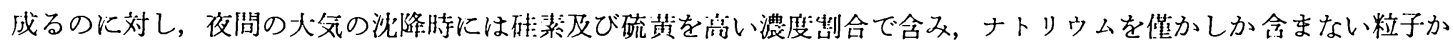

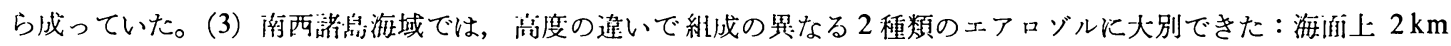
程度の海洋大父中ではェアロゾルが主に海水の組成に類似の組成を持つ粒子から成っているのに対し，その上空では 海水の組成に比べて硅素及び硫黄を吼濃度制合で含む粒子から成っていた。これらの硅菜, ナトリウムと硫黄の元 来組成から粒子中の值酸塩, 海塩と硫酸塩成分の相対含㭙割合を見积った。これらの解析によって, 硅酸掹と硫酸塩 成分を高い濃度割合で含み，海塩を微星しか含まない直径 $0.5 \mu \mathrm{m}$ 以上の㳸合粒子が本州から沖縄に至る日本上空の 白由大父中に広く分布することが示唆された。
\end{abstract}

